\title{
Fine-scale genetic structure and dispersal in cooperatively breeding apostlebirds
}

\author{
IAIN A. WOXVOLD, ${ }^{*}$ GREG J. ADCOCK*+ and RAOUL A. MULDER* \\ *Department of Zoology, University of Melbourne, Vic. 3010, Australia, +School of Botany and Zoology, Australian National \\ University, Canberra, ACT 0200, Australia
}

\begin{abstract}
In cooperatively breeding species, restricted dispersal of offspring leads to clustering of closely related individuals, increasing the potential both for indirect genetic benefits and inbreeding costs. In apostlebirds (Struthidea cinerea), philopatry by both sexes results in the formation of large (up to 17 birds), predominantly sedentary breeding groups that remain stable throughout the year. We examined patterns of relatedness and fine-scale genetic structure within a population of apostlebirds using six polymorphic microsatellite loci. We found evidence of fine-scale genetic structure within the study population that is consistent with behavioural observations of short-distance dispersal, natal philopatry by both sexes and restricted movement of breeding groups between seasons. Global $F_{\mathrm{ST}}$ values among breeding groups were significantly positive, and the average level of pairwise relatedness was significantly higher for individuals within groups than between groups. For individuals from different breeding groups, geographical distance was negatively correlated with pairwise relatedness and positively correlated with pairwise $F_{\mathrm{ST}}$. However, when each sex was examined separately, this pattern was significant only among males, suggesting that females may disperse over longer distances. We discuss the potential for kin selection to influence the evolution and maintenance of cooperative breeding in apostlebirds. Our results demonstrate that spatial genetic structural analysis offers a useful alternative to field observations in examining dispersal patterns of cooperative breeders.
\end{abstract}

Keywords: cooperative breeding, genetic structure, isolation by distance, microsatellites, Struthidea cinerea

Received 1 January 2006; revision accepted 2 May 2006

\section{Introduction}

In most cooperative breeders, social groups are formed primarily through the retention of philopatric offspring, and dispersal is often limited to short distances from the natal territory by one or both sexes (Cockburn 1998; Ekman et al. 2004). Restricted or sex-biased dispersal results in clustering of individuals with respect to their relatedness (Sugg et al. 1996), and the resulting pattern of gene flow has important implications for the population biology and behavioural ecology of cooperative societies. For instance, genetic structure within a population can facilitate kin selection (Russell \& Hatchwell 2001), since indirect genetic benefits will promote the evolution of helping only if

Correspondence: Iain Woxvold, Fax: +61 38344 7909;

E-mail: iwoxvold@unimelb.edu.au helpers are, on average, more closely related to recipient offspring than they are to other individuals randomly selected from the population (Queller \& Goodnight 1989; Queller 1994).

High levels of relatedness among the members of a cooperative group will also increase the likelihood of incestuous matings (Koenig \& Haydock 2004). Inbreeding has been linked to a significant loss of fitness in many species (Keller \& Waller 2002), including some cooperative breeders (Brown \& Brown 1998; Daniels \& Walters 2000; Spottiswoode \& Møller 2003). Such costs of inbreeding may in turn influence patterns of dispersal in cooperative societies (Greenwood 1980; Pusey \& Wolf 1996). In many cooperative bird species, philopatry is biased toward one sex (normally males: Woolfenden \& Fitzpatrick 1978; Greenwood 1980; Rabenold 1990) and/or members of one sex (normally females) typically disperse over longer 
distances (Walters et al. 2004), resulting in an effective spatial separation of kin.

The social structure of a population is often estimated by observing recruitment and dispersal of individuals in the field. However, recruitment and dispersal can be difficult to measure directly because the temporal and spatial limitations imposed on most studies restrict the detection of rare events, or those that involve large distances (Koenig et al. 1996). An alternative approach is to assess dispersal indirectly by examining the genetic structure within and between populations (Koenig et al. 1996; Sugg et al. 1996). Numerous studies have evaluated genetic structure over a large geographical area, but relatively few have analysed fine-scale genetic structure within avian populations. Most of these have demonstrated the existence of microspatial structuring among birds with lek mating systems (Höglund et al. 1999; Shorey et al. 2000; Höglund \& Shorey 2003; Bouzat \& Johnson 2004). Microspatial structuring is also expected to occur in many cooperatively breeding species, where restricted dispersal and high levels of philopatry may decrease genetic variation within breeding groups, relative to genetic differentiation between groups. To date, however, few studies have assessed fine-scale genetic structuring in cooperatively breeding birds (Painter et al. 2000; Double et al. 2005).

In this study, we examine patterns of fine-scale genetic structuring in the cooperatively breeding apostlebird Struthidea cinerea (Corcordacidae), a medium-sized $(33 \mathrm{~cm}$, $130 \mathrm{~g}$ ), sexually monomorphic, ground-foraging passerine that inhabits dry woodlands in eastern Australia. Apostlebirds are highly social and live in sedentary groups with between three and 20 members that remain together throughout the year (Woxvold 2004). Breeders rely heavily on helpers for successful reproduction, and no unassisted pair has been reported to fledge young (Woxvold \& Magrath 2005). Both sexes delay dispersal, and comprise the majority of new recruits into established breeding groups (87.4\%), although group membership is occasionally augmented by immigrants of either sex (Woxvold 2004).

Using a set of six polymorphic microsatellite loci, we first ask whether patterns of gene flow in apostlebirds are consistent with observations of a high level of natal philopatry by evaluating the level of genetic structuring within the population and comparing patterns of relatedness among birds within and between breeding groups. To evaluate prior observations of short-distance dispersal by apostlebirds, we then compare the genetic differentiation among groups with their geographical separation; gene flow resulting from restricted dispersal is expected to lead to greater similarity among sedentary groups living closer together ('isolation-by-distance', Wright 1943). Finally, potential differences in dispersal strategies by males and females are examined by assessing patterns of relatedness,

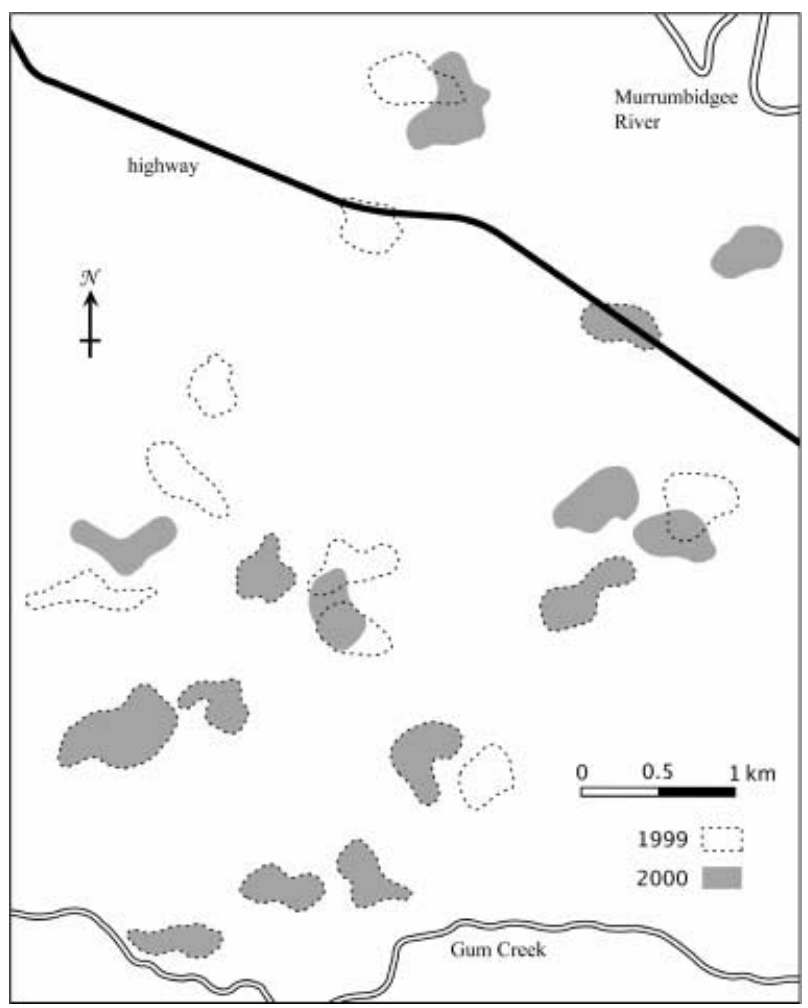

Fig. 1 Map of the study area showing the distribution of breeding groups of apostlebirds $(1999, n=18 ; 2000, n=15)$ used in genetic structural and isolation-by-distance analyses. Distance between groups was calculated using nest sites. Territorial boundaries were estimated from censuses of group membership taken weekly (1999) or every 10 days (2000).

genetic structuring and isolation by distance (IBD) separately for each sex.

\section{Materials and methods}

\section{Study population}

The study was conducted on private farmland in southern New South Wales $\left(34^{\circ} 34^{\prime} \mathrm{S}, 145^{\circ} 45^{\prime} \mathrm{E}\right)$, where apostlebirds inhabited discrete patches of woodland separated by expanses of grassland. We monitored the breeding activities of resident groups over three seasons (August to January) from 1998 to 2000, although sampling was sufficient to analyse population genetic structure only during 1999 and 2000. Breeding groups included in genetic analyses occupied c. 3100 ha of the study area, within which most individuals were sampled (Fig. 1). The proportion of birds (excluding fledglings) sampled in each season was $83.7 \%(1999, n=147)$ and $79.7 \%$ (2000, $n=177)$. Group size at the start of each season ranged from 3 to 17 birds, and membership was monitored at least once every 10 days. During each census, the focal 
Table 1 Dispersal data for 13 apostlebirds that emigrated to established breeding groups. Dispersal distance was measured as the distance between boundaries of breeding territories. Territorial boundaries were inferred from observations made during regular ( $\leq 10$ days) censuses of each group

\begin{tabular}{|c|c|c|c|c|}
\hline & & No. males & No. females & Sex unknown \\
\hline Banded prior to dispersal & & 5 & 2 & 1 \\
\hline \multirow[t]{3}{*}{ Dispersal distance: } & $<50 \mathrm{~m}$ & 2 & 1 & 1 \\
\hline & $0.75-1.0 \mathrm{~km}$ & 2 & 1 & \\
\hline & $1.5 \mathrm{~km}$ & 1 & & \\
\hline Banded after dispersal & & 2 & 2 & \\
\hline Total & & 7 & 4 & 2 \\
\hline
\end{tabular}

group was followed for 10-15 min after first contact, with positions recorded on an aerial photograph of the study site (1:12 820). Territorial boundaries were inferred from the farthest distances that group members travelled before turning back towards the nest. Distances between the nests and territorial boundaries of separate groups were calculated from the study site aerial photograph.

During our research, most new recruits into established breeding groups were offspring that delayed dispersal (87.4\%, $n=103$; Woxvold 2004). However, group membership was partly augmented by immigration. Among immigrants of known gender, there was no apparent sex-bias in either the likelihood or distance of dispersal, although the sample size was small (Table 1). Of eight immigrants banded prior to dispersal, seven relocated within $1 \mathrm{~km}$ of the breeding territory in which they were originally marked, although the origin of unbanded birds $(n=5)$ was unknown (Table 1).

Adults were captured in mist nets (12 m, $63 \mathrm{~mm}$ mesh). Each bird was fitted with a metal band (Australian Bird and Bat Banding Scheme) and a unique combination of coloured darvic bands. A blood sample was taken from each adult $(25-100 \mu \mathrm{L})$ by brachial venipuncture using a $27 \mathrm{G}$ needle. A smaller sample $(10-50 \mu \mathrm{L})$ was taken from the medial metatarsal vein of each nestling when first captured. Blood samples were immediately transferred into $750 \mu \mathrm{L}$ of either lysis buffer $(0.1 \mathrm{M}$ Tris- $\mathrm{HCl}, \mathrm{pH} 8.0 ; 0.1 \mathrm{M}$ EDTA, pH 7.5; $10 \mathrm{~mm} \mathrm{NaCl;0.5 \%} \mathrm{SDS)} \mathrm{or} 100 \%$ ethanol and stored at $4{ }^{\circ} \mathrm{C}$ for up to 10 months. DNA was extracted using a salting-out procedure (Bruford et al. 1992) and sex was determined using the method described by Fridolfsson \& Ellegren (1999).

\section{Isolation of novel polymorphic microsatellite markers}

Genomic DNA of apostlebirds was enriched for fragments containing GAAA and GT repeats which were then used to make a plasmid library and screened for repeat-containing colonies using the method of Gardner et al. (1999) as modified by Adcock \& Mulder (2002). Positive clones were amplified in $50-\mu \mathrm{L}$ reactions and the polymerase chain reaction (PCR) product purified using a QIAquick PCR purification kit (QIAGEN). Amplified DNA $250 \mathrm{ng}$ was sequenced commercially (SUPAMAC).

Primers were designed to flank repeated regions using PRIMER 3 (Rozen \& Skaletsky 2000). Primer pairs that yielded specific products of appropriate size following optimization of PCR conditions were subsequently tested for polymorphism. A 5'-M13 tail (5'-CACGACGTTGTAAAACGAC) was added to one primer from each pair for use in the dyelabelling method outlined by Boutin-Ganache et al. (2001). Polymorphism was assessed by typing 16 putatively unrelated apostlebirds (separate breeding groups). Each $10-\mu \mathrm{L}$ reaction contained 30-100 ng of DNA, $0.15 \mathrm{U}$ of Taq polymerase and reaction buffer (Promega: $10 \mathrm{~mm}$ Tris$\mathrm{HCl}, 50 \mathrm{~mm} \mathrm{KCl}, 0.1 \%$ Triton X-100), $3 \mathrm{~mm}$ of $\mathrm{MgCl}_{2}$, $200 \mu \mathrm{M}$ dNTPs (Promega), an M13 primer (200 nM) 5'labelled with a Beckman Coulter dye (D2, D3 or D4), and the locus-specific tailed (15 $\mathrm{nM})$ and un-tailed (200 nM) primers. Reactions were run in $0.2-\mathrm{mL}$ microtitre plate wells (Greiner) overlaid with a drop of mineral oil (Sigma) on a Corbett Research PC-960C thermocycler. The thermal cycling program comprised an initial cycle of $90 \mathrm{~s}$ at $94^{\circ} \mathrm{C}$, followed by 40 cycles of $20 \mathrm{~s}$ at $94^{\circ} \mathrm{C}, 20 \mathrm{~s}$ at the optimal annealing temperature, and $90 \mathrm{~s}$ at $73{ }^{\circ} \mathrm{C}$. PCR products $(0.25 \mu \mathrm{L})$ were electrophoresed on a Beckman Coulter 8000XL automated sequencer using the CEQ 8000XL fragment analysis kit (Beckman Coulter). Fragment sizes were determined using the Beckman Coulter 8000XL fragment analysis software. The software package cERvus (Marshall et al. 1998) was used to calculate allele frequencies and expected and observed heterozygosities.

\section{Population genetic structure}

We used several methods to genetically corroborate our behavioural observations of high levels of philopatry and short-distance dispersal by apostlebirds. First, the extent of genetic structuring within the population was investigated using an analysis of molecular variance (AMOVA) framework in ARLEQUIN (version 2.000; Schneider et al. 2000). This method apportions the total genetic variance into hierarchical 
Table 2 Characterization of six microsatellite loci found to be polymorphic in the apostlebird Struthidea cinerea. The M13 prefix in the primer sequence indicates the site of attachment of a $5^{\prime} \mathrm{M} 13$ tail (CACGACGTTGTAAAACGAC). The final annealing temperature ( $\left.T_{\mathrm{M}}\right)$ is in ${ }^{\circ} \mathrm{C}$, and the $\mathrm{MgCl}_{2}$ concentration in mM. The number of alleles $\left(N_{\mathrm{A}}\right)$ and observed size range for each in base pairs (bp) was calculated for 254 individuals from 20 breeding groups. Observed $\left(H_{\mathrm{O}}\right)$ and expected $\left(H_{\mathrm{E}}\right)$ heterozygosities were calculated using 43 birds from 20 groups. Five loci were revealed through cross-amplification with primers developed for Corcorax melanorhamphos ${ }^{1}$ and Petroica goodenovii $^{2}$. The cloned sequence of Sci1 has been deposited with GenBank under the Accession no. AY642592. Sci1 was also found to be polymorphic in C. melanorhamphos

\begin{tabular}{|c|c|c|c|c|c|c|c|c|}
\hline Locus & Repeat motif & Primer sequence $\left(5^{\prime}-3^{\prime}\right)$ & $T_{\mathrm{M}}$ & $\left(\mathrm{MgCl}_{2}\right)$ & $N_{\mathrm{A}}$ & bp & $H_{\mathrm{O}}$ & $H_{\mathrm{E}}$ \\
\hline Sci1 & $\begin{array}{l}(\mathrm{GAAA})_{7} \mathrm{AAAA}(\mathrm{GAAA})_{26} \\
\mathrm{GA}(\mathrm{GAAA})_{22}(\mathrm{GA})_{6}(\mathrm{GAAAGAGA})_{2}\end{array}$ & $\begin{array}{l}\text { F: M13-TGAAATAACTTCGATAGTGTCAGG } \\
\text { R: GAACCGAACAAAACTTTACTGTG }\end{array}$ & 52 & 3 & 27 & $222-414$ & 0.953 & 0.921 \\
\hline CmeG51 & - & - & 52 & 3 & 7 & $193-221$ & 0.814 & 0.757 \\
\hline CmeG91 & - & - & 50 & 3 & 7 & $257-286$ & 0.721 & 0.793 \\
\hline $\mathrm{CmeH}_{21}$ & - & - & 50 & 3 & 5 & $155-171$ & 0.628 & 0.669 \\
\hline $\operatorname{Pgm} 2^{2}$ & - & - & 52 & 3 & 4 & $223-239$ & 0.558 & 0.565 \\
\hline $\operatorname{Pgm} 4^{2}$ & - & - & 52 & 3 & 14 & $272-424$ & 0.837 & 0.860 \\
\hline
\end{tabular}

1Beck et al. (2003); ${ }^{2}$ Dowling et al. (2003).

components (within individuals, and within and among breeding groups), and was used to compute Wright's (1951) fixation index $F_{\mathrm{ST}}$ for all individuals. The significance of the overall $F$-statistic was derived from null distributions generated from 5000 random permutations between individuals among breeding groups (= subpopulations). The degree of relatedness $(R)$ between birds within and between breeding groups was then calculated and compared using a regression approach (Queller \& Goodnight 1989) implemented by the program RELATEDNESS 5.0 (Goodnight \& Queller 1999). Standard errors and $95 \%$ confidence intervals for mean $R$ values were obtained by jackknifing across loci. Sex differences in population structure were characterized by calculating relatedness between pairs of the same sex. Finally, in a continuous population, restricted dispersal is expected to result in a pattern of isolation by distance (Wright 1943), whereby genetic differentiation increases linearly with the natural log of the geographical distance between individuals in a two-dimensional plane (Rousset 2000). Mantel tests (10 000 permutations) were used to examine the relationship between geographical distance (ln $\mathrm{km}$ ) and the genetic distance between pairs of birds in different groups (Fig. 1), as defined by (i) $F_{\mathrm{ST}} /\left(1-F_{\mathrm{ST}}\right)$ and (ii) pairwise $R$, using the program IBD version 1.52 (Isolation By Distance; Bohonak 2002). We tested for a potential sex difference in dispersal strategies by analysing patterns of IBD for males and females separately.

\section{Results}

\section{Detection and characterization of polymorphic loci}

Of 436 colonies screened from the GAAA-enriched library, 15 positive clones were identified and sequenced. Nine of these contained more than five repeats and included flanking sequences suitable for primer design. From the GT library, 11 positives were identified from 136 colonies, with primers designed for six. A single locus (Sci1; GenBank Accession no. AY642592) was found to be polymorphic. This was supplemented with five primer pairs developed for microsatellites isolated in two other Australian passerines, the white-winged chough (Corcorax melanorhamphos, three loci, Beck et al. 2003) and the red-capped robin (Petroica goodenovii, two loci, Dowling et al. 2003). Table 2 shows the primer sequence for Sci1, and the optimal annealing temperature, $\mathrm{MgCl}_{2}$ concentration, number of alleles found and observed and expected heterozygosities.

Sci1 was tested for cross-species amplification in the white-winged chough, the only other member of the family Corcoracidae (Schodde \& Mason 1999). Under conditions optimized for use in apostlebirds, Sci1 amplified fragments of nine different sizes from eight putatively unrelated individuals, suggesting suitability for use in parentage analysis.

\section{Population genetic structure}

Overall population $F_{\mathrm{ST}}$ was significantly greater than zero (1999: 0.1749, 2000: 0.1901; $P<0.001$ both years), indicating that a significant amount of the genetic variance within the population existed between social units. Accordingly, average within-group relatedness $\left(R_{\mathrm{w}}\right)$ was significantly higher than that for pairs between groups $\left(R_{\mathrm{b}}\right)$ (Table 3 ). Average $R_{\mathrm{w}}$ was much greater than zero, while average $R_{\mathrm{b}}$ was less than zero (Table 3). A similar pattern was observed when the sexes were analysed separately (Table 3). Average pairwise relatedness between males within groups was similar to that of females within groups $\left(R_{\mathrm{w} \text {-male }}-R_{\mathrm{w} \text {-female }}\right.$ : $1999=-0.0133, P=0.696 ; 2000=0.0154, P=0.634)$, consistent 
Table 3 Average pairwise relatedness within $\left(R_{\mathrm{w}}\right)$ and between $\left(R_{\mathrm{b}}\right)$ apostlebird breeding groups during 1999 and 2000. Sample sizes $(n)$ indicate the number of individuals used in each set of comparisons. $P$ values denote the statistical significance of the difference between $R_{\mathrm{w}}$ and $R_{\mathrm{b}}$. When analysing each sex, samples used in within-group analyses were sometimes smaller than between-group analyses due to the presence of small breeding groups where data for only one member for each sex was available, precluding comparison between individuals. Standard errors and 95\% confidence intervals were obtained by jackknifing across loci

\begin{tabular}{|c|c|c|c|c|c|c|c|c|c|}
\hline & \multicolumn{4}{|c|}{ Within-group } & \multicolumn{4}{|c|}{ Between-group } & \multirow[b]{2}{*}{$R_{\mathrm{w}}-R_{\mathrm{b}}$} \\
\hline & $n$ & $R_{\mathrm{w}}$ & SE & $95 \% \mathrm{CI}$ & $n$ & $R_{\mathrm{b}}$ & SE & $95 \% \mathrm{CI}$ & \\
\hline \multicolumn{10}{|l|}{ All } \\
\hline 1999 & 114 & 0.3467 & 0.0537 & 0.1379 & 114 & -0.0352 & 0.0052 & 0.0135 & $0.3819^{*}$ \\
\hline 2000 & 112 & 0.3643 & 0.0535 & 0.1375 & 112 & -0.0412 & 0.0054 & 0.0139 & $0.4054^{*}$ \\
\hline \multicolumn{10}{|l|}{ Male } \\
\hline 1999 & 69 & 0.3791 & 0.0631 & 0.1623 & 70 & -0.0366 & 0.0163 & 0.0420 & $0.4157^{*}$ \\
\hline 2000 & 61 & 0.4061 & 0.0662 & 0.1701 & 61 & -0.0515 & 0.0176 & 0.0452 & $0.4576^{*}$ \\
\hline \multicolumn{10}{|l|}{ Female } \\
\hline 1999 & 39 & 0.3923 & 0.0501 & 0.1287 & 44 & -0.0200 & 0.0118 & 0.0303 & $0.4123^{*}$ \\
\hline 2000 & 48 & 0.3908 & 0.0371 & 0.0954 & 51 & -0.0223 & 0.0167 & 0.0429 & $0.4131^{*}$ \\
\hline
\end{tabular}

${ }^{*} P<0.0001$.

with observations that both sexes delay dispersal, and that there is no apparent sex bias among immigrants into established groups.

There was a strong pattern of IBD observed in the population as a whole during both 1999 and 2000. Pairwise relatedness decreased significantly with geographical distance (ln-km) between breeding groups during both years (Mantel test: $1999, P=0.007, n=153 ; 2000, P=0.001, n=105$ ). A similar though weaker correlation was observed between genetic distance as measured by $F_{\mathrm{ST}} / 1-F_{\mathrm{ST}}$ and geographical distance (1999: $P=0.030 ; 2000: P=0.051$ ). When the sexes were analysed separately, males showed a stronger pattern of IBD than females. Among males, geographical separation was significantly and inversely related to pairwise relatedness (1999: $P=0.008, n=153$, Fig. 2a; 2000: $P<0.001, n=105$, Fig. $2 b)$ and positively correlated with genetic distance (1999: $P=0.013$ ), although this trend was not significant during $2000(P=0.054)$. In contrast, neither kinship nor genetic distance between females was significantly related to geographical separation in any year (pairwise $R$ : 1999: $P=0.134, n=136$, Fig. 2(c); 2000: $P=0.119$, $n=91$, Fig. 2(d); $F_{\mathrm{ST}} / 1-F_{\mathrm{ST}}: 1999: P=0.151, n=66 ; 2000$ : $P=0.051, n=55)$.

\section{Discussion}

Our results reveal the existence of fine-scale spatial genetic structure within a population of apostlebirds. Significant global $F_{\mathrm{ST}}$ values, overall patterns of IBD, and higher levels of relatedness among birds within groups than among birds between groups are all consistent with behavioural observations of natal philopatry by both sexes, restricted dispersal over short distances, and the highly sedentary (between-season) nature of most social units (Woxvold
2004). While many birds exhibit restricted dispersal (Greenwood 1980), few studies have analysed fine-scale genetic structure within avian populations (e.g. Shorey et al. 2000; Bouzat \& Johnson 2004), and this is one of the first studies to demonstrate this pattern in a nonlekking species (Piertney et al. 1999; Painter et al. 2000; Double et al. 2005).

Genetic structuring within cooperative societies is an important prerequisite for the development and maintenance of helping behaviour. Indirect genetic benefits accrued by a helper are the product of (i) its contribution to the number of young raised by the group, and (ii) the coefficient of relatedness between helper and recipient. It has previously been demonstrated that apostlebird helpers enhance the production of nondescendent offspring (Woxvold \& Magrath 2005).

However, for kin selection to influence the maintenance of cooperative breeding the degree of relatedness between members of a breeding group must be higher than that of average pairings between groups (Queller \& Goodnight 1989; Queller 1994). Our results confirm this pattern (previously based on short-term observations of delayed dispersal in the field) for the present study.

Restricted dispersal and patterns of IBD may also mitigate the reduction of indirect genetic benefits accruing to philopatric helpers in the event of successful matings by an immigrant. Such events are likely to be common given the importance of avoiding incestuous mating (Koenig \& Haydock 2004). In our study population, we observed both occasional polygamy (4/15 group-seasons where mating system resolved) and divorce ( $n=1$ group; Woxvold 2005), indicating that nonbreeding group members varied in their degree of relatedness to breeding birds. Moreover, in a detailed analysis of nesting behaviour 
1999
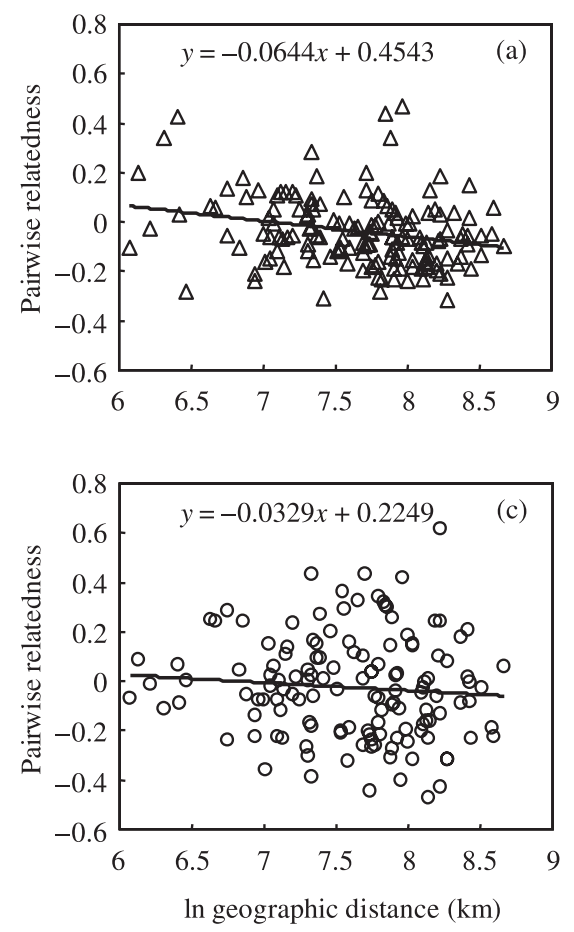

2000
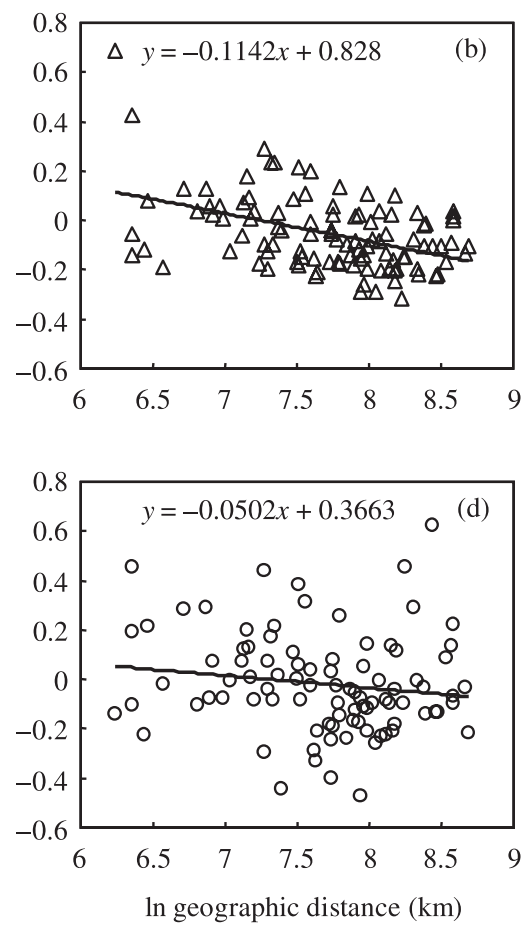

Fig. 2 Relatedness between pairs of male (a, b; open triangles) and female (c, d; open circles) apostlebirds in different breeding groups in relation to the logarithm of geographical distance $(\mathrm{km})$ between groups during 1999 (a, c) and 2000 (b, d).
(Woxvold 2005; Woxvold et al. in press), most nonbreeding members of these groups continued to provision nestlings. In such circumstances active helpers may enjoy a range of direct genetic benefits (skills acquisition, improved chances of future independent reproduction, etc.), although many will accrue lower indirect returns than those assisting first-order relatives. However, where dispersal normally occurs over short distances and neighbours are more closely related than birds from distant groups, mating by immigrants from nearby groups may not reduce the relatedness between helpers and recipients as much as random dispersal.

Our data revealed a stronger pattern of IBD among males than among females, suggesting that males tend to disperse over shorter distances. It is possible that IBD was not significant among females due to the smaller sample in the population (type II error). Nevertheless, insofar as these results do reflect more restricted dispersal by males, they have important consequences for our understanding of the comparative behavioural ecology of male and female apostlebirds. In the absence of associative cues, birds may have difficulty recognizing unfamiliar kin following dispersal (Koenig \& Haydock 2004; Sharp et al. 2005), and a sex-bias in dispersal distance will minimize the chances of cohabiting with a relative of the opposite sex. In most cooperative birds, males are the more philopatric sex, and are more likely to acquire breeding status in or near the natal territory (Komdeur \& Edelaar 2001; Cockburn et al. 2003; Walters et al. 2004). Accordingly, females settle further from their natal territory in most cooperative species for which data are available, a pattern that has been interpreted as a mechanism for avoiding close inbreeding (Walters et al. 2004). As yet, there are too few direct observations of dispersal by apostlebirds to indicate which sex is more likely to breed in the natal neighbourhood. However, genetic analysis suggests that females may employ a similar inbreeding avoidance strategy to that observed in other cooperative species.

Our conclusions about philopatry and dispersal from genetic structural analysis of the study population are similar to those obtained from direct observations of individuals of known identity. However, our genetic data also revealed that male and female apostlebirds may adopt subtly different dispersal strategies, a pattern which was not evident from the small sample of known dispersal events. Detecting such subtle differences in the field would require a lengthy study conducted over a large spatial area. Thus, molecular analysis of spatial genetic structure offers a useful and cost-effective alternative to field observations in examining dispersal patterns of cooperative breeders.

\section{Acknowledgements}

Many thanks to the Ryan family for permission to work on their property. This research was supported by grants from The Holsworth Wildlife Research Fund, The Norman Wettenhall Foundation, Australian Geographic, The American Museum of Natural History, The Royal Zoological Society of NSW, and Birds Australia (VicGroup). IAW was supported by an Australian 
Research Council Large Grant awarded to Jan Komdeur, and a stipend from the Faculty of Science, University of Melbourne. RAM was supported by a grant from the Australian Research Council. Thanks to all who assisted in the field, particularly Eron Chapman, Michael Magrath, Rebecca McIntosh, Emma and Helen Burdekin, Eric Woxvold, Bryony Anderson, John Sandow, Mark Johnson, Telford Scully, Sonia Orchard and Andrew Barnes. Peter Dunn and Linda Whittingham provided valuable comments on an earlier version of the manuscript.

\section{References}

Adcock GJ, Mulder RA (2002) Polymorphic microsatellite loci for paternity analysis in the Madagascar paradise flycatcher (Terpsiphone mutata: Aves). Molecular Ecology Notes, 2, 287-289.

Beck N, Peakall R, Heinsohn R (2003) Isolation and characterization of polymorphic microsatellite markers in the white-winged chough (Corcorax melanorhamphos). Molecular Ecology Notes, 3, 586-588.

Bohonak AJ (2002) IBD (Isolation By Distance): a program for analyses of isolation by distance. Journal of Heredity, 93, 153-154.

Boutin-Ganache I, Raposo M, Raymond M, Descepper CF (2001) M13-tailed primers improve the readability and usability of microsatellite analyses performed with two different allelesizing methods. BioTechniques, 31, 1-3.

Bouzat JL, Johnson K (2004) Genetic structure among closely spaced leks in a peripheral population of lesser prairie chickens. Molecular Ecology, 13, 499-505.

Brown JL, Brown ER (1998) Are inbred offspring less fit? Survival in a natural population of Mexican jays. Behavioral Ecology, 9, 60-63.

Bruford MW, Hanotte O, Brookfield JFY, Burle T (1992) Single locus and multi-locus fingerprinting. In: Molecular Genetic Analysis of Populations - a Molecular Approach (ed. Hoelzel AR), pp. 227-229. IRL Press, Oxford.

Cockburn A (1998) Evolution of helping behavior in cooperatively breeding birds. Annual Review of Ecology and Systematics, 29, 141177.

Cockburn A, Osmond HL, Mulder RA, Green DJ, Double MC (2003) Divorce, dispersal and incest avoidance in the cooperatively breeding superb fairy-wren Malurus cyaneus. Journal of Animal Ecology, 72, 189-202.

Daniels SJ, Walters JR (2000) Inbreeding depression and its effects on natal dispersal in red-cockaded woodpeckers. The Condor, 102, 482-491.

Double MC, Peakall R, Beck NR, Cockburn A (2005) Dispersal, philopatry and infidelity: dissecting local genetic structure in superb fairy-wrens (Malurus cyaneus). Evolution, 59, 625-635.

Dowling DK, Adcock GJ, Mulder RA (2003) Novel polymorphic micrsatellite markers for paternity analysis in the red-capped robin (Petroica goodenovii: Aves). Molecular Ecology Notes, 3, 517519.

Ekman J, Dickinson JL, Hatchwell BJ, Griesser M (2004) Delayed dispersal. In: Ecology and Evolution of Cooperative Breeding in Birds (eds Koenig WD, Dickinson JL), pp. 35-47. Cambridge University Press, Cambridge.

Fridolfsson A-K, Ellegren H (1999) A simple and universal method for molecular sexing of non-ratite birds. Journal of Avian Biology, 30, 116-121.

Gardner MG, Cooper SJB, Bull CM, Grant WN (1999) Isolation of microsatellite loci from a social lizard, Egernia stokesii, using a modified enrichment procedure. Journal of Heredity, 90, 301-304.
Goodnight KF, Queller DC (1999) RELATEDNEsS 5.0 (Software). In: 5.0 Edn. Goodnight Software for Population Biology (http:// www.gsoftnet.us/GSoft.html).

Greenwood PJ (1980) Mating systems, philopatry and dispersal in birds and mammals. Animal Behaviour, 28, 1140-1162.

Höglund J, Shorey L (2003) Local genetic structure in a whitebearded manakin population. Molecular Ecology, 12, 2457-2463.

Höglund J, Alatalo RV, Lundberg A, Rintamaki PT, Lindell J (1999) Microsatellite markers reveal the potential for kin selection on black grouse leks. Proceedings of the Royal Society of London. Series B, Biological Sciences, 266, 813-816.

Keller LF, Waller DM (2002) Inbreeding effects in wild populations. Trends in Ecology \& Evolution, 17, 230-241.

Koenig WD, Haydock J (2004) Incest and incest avoidance. In: Ecology and Evolution of Cooperative Breeding in Birds (eds Koenig WD, Dickinson JL), pp. 142-156. Cambridge University Press, Cambridge.

Koenig WD, Van Vuren D, Hooge PN (1996) Detectability, philopatry, and the distribution of dispersal distances in vertebrates. Trends in Ecology \& Evolution, 11, 514-517.

Komdeur J, Edelaar P (2001) Male Seychelles warblers use territory budding to maximize lifetime fitness in a saturated environment. Behavioral Ecology, 12, 706-715.

Marshall T, Slate J, Kruuk L, Pemberton J (1998) Statistical confidence for likelihood-based paternity inference in natural conditions. Molecular Ecology, 7, 639-655.

Painter JN, Crozier RH, Poiani A, Robertson RJ, Clarke MF (2000) Complex social organization reflects genetic structure and relatedness in the cooperatively breeding bell miner, Manorina melanophrys. Molecular Ecology, 9, 1339-1347.

Piertney SB, MacColl ADC, Lambin X, Moss R, Dallas JF (1999) Spatial distribution of genetic relatedness in a moorland population of red grouse (Lagopus lagopus scoticus). Biological Journal of the Linnean Society, 68, 317-331.

Pusey AE, Wolf M (1996) Inbreeding avoidance in animals. Trends in Ecology \& Evolution, 11, 201-206.

Queller DC (1994) Genetic relatedness in viscous populations. Evolutionary Ecology, 8, 70-73.

Queller DC, Goodnight KF (1989) Estimating relatedness using genetic markers. Evolution, 43, 258-275.

Rabenold KN (1990) Campylorhynchus wrens: the ecology of delayed dispersal and cooperation in the Venezuelan savanna. In: Cooperative Breeding in Birds: Long-Term Studies of Ecology and Behavior (eds Stacey PB, Koenig WD), pp. 159-196. Cambridge University Press, Cambridge.

Rousset F (2000) Genetic differentiation between individuals. Journal of Evolutionary Biology, 13, 58-62.

Rozen S, Skaletsky HJ (2000) PRIMER 3 on the WWW for general users and for biologist programmers. In: Bioinformatics Methods and Protocols: Methods in Molecular Biology (eds Krawetz S, Misener S), pp. 365-386. Humana Press, Totowa, NJ.

Russell AF, Hatchwell BJ (2001) Experimental evidence for kinbiased helping in a cooperatively breeding vertebrate. Proceedings of the Royal Society of London. Series B, Biological Sciences, 268, 2169-2174.

Schneider S, Roessli D, Excoffier L (2000) ARLEQUIN ver 2.000, a Software for Population Genetics Data Analysis. University of Geneva, Geneva.

Schodde R, Mason IJ (1999) The Directory of Australian Birds: Passerines. CSIRO Publishing, Melbourne.

Sharp SP, McGowan A, Wood MJ, Hatchwell BJ (2005) Learned kin recognition cues in a social bird. Nature, 434, 1127-1130. 
3146 I. A. WOXVOLD, G. J. ADCOCK and R. A. MULDER

Shorey L, Piertney S, Stone J, Höglund J (2000) Fine-scale genetic structuring on Manacus manacus leks. Nature, 408, 352-353.

Spottiswoode C, Møller AP (2003) Genetic similarity and hatching success in birds. Proceedings of the Royal Society of London. Series B, Biological Sciences, 271, 267-272.

Sugg DW, Chesser RK, Dobson FS, Hoogland JL (1996) Population genetics meets behavioral ecology. Trends in Ecology \& Evolution, 11, 338-342.

Walters JR, Cooper CB, Daniels SJ, Pasinelli G, Schiegg K (2004) Conservation biology. In: Ecology and Evolution of Cooperative Breeding in Birds (eds Koenig WD, Dickinson JL), pp. 197-209. Cambridge University Press, Cambridge.

Woolfenden GE, Fitzpatrick JW (1978) Inheritance of territory in group breeding birds. Bioscience, 28, 104-108.

Woxvold IA (2004) Breeding ecology and group dynamics of the apostlebird. Australian Journal of Zoology, 52, 561-581.

Woxvold IA (2005) Social organization, cooperative breeding and sex allocation in the apostlebird, Struthidea Cinerea. PhD Thesis, University of Melbourne, Australia.

Woxvold IA, Magrath MJL (2005) Helping enhances multiple components of reproductive success in the cooperatively breeding apostlebird. Journal of Animal Ecology, 74, 1039-1050.

Woxvold IA, Mulder RA, Maghrath MJL (in press) Contributions to care vary with age, sex, breeding status and group size in the cooperatively breeding apostlebird. Animal Behaviour.

Wright S (1943) Isolation by distance. Genetics, 28, 114-138.

Wright S (1951) The genetical structure of populations. Annals of Eugenics, 15, 323-354.

Iain Woxvold's research focuses on the behavioural ecology of cooperatively breeding Australian passerines. His main research interests include the evolution and maintenance of cooperative breeding and sex allocation in avian societies. Raoul Mulder is a senior lecturer at the University of Melbourne, and his research focuses on ornamentation, sexual selection and cooperative breeding in birds. Greg Adcock is a molecular ecologist at the Australian National University. His research interests include conservation and the processes that maintain population diversity and lead to adaptive changes in morphology and behaviour. 